\title{
An intelligent seat's system for better ergonomics and Human- Computer Interaction
}

\author{
Jin $\mathrm{Cao}^{1 *}$ Yufei Wang ${ }^{2}$ \\ ${ }^{1}$ Department of Industrial Design, graduate student of Industrial design, Rhode Island School of \\ Design, Providence, Rhode Island, USA \\ ${ }^{2}$ Department of Industrial Design, undergraduate student of industrial design, University of Science \\ \& Technology, Beijing, China \\ *jcao01@risd.edu (Jin Cao)
} Keywords: Ergonomics; $\mathrm{HCl}$; action Innovation; Aesthetics and visual modeling; Structure
redesign with low weight and cost; Functional system environment

\begin{abstract}
As technology advances, new tech influence the seat design with better ergonomics and new HCI, considering the cost of replacement, the airline companies does not replace seat system. But designers should carry out a series of re-optimized design in ergonomics and HCI.This paper describes an intelligent seat's system, which is supposed to be used for the airplanes or similar conditions. This system consists of redesigned ergonomics and HCI in original seat's systems. The mainly redesign part is the aesthetics and visual modeling for people to receive visual information, the ergonomics part for person to receive tactile information, new user's action innovation for people to receive and output information, the redesign of the structure of the system with low weight and cost, the functional system environment for people to receive information from human through movement in multiple environment. The purpose of the redesign is to improve the HCI system with new tech and interaction.
\end{abstract}

\section{Introduction}

This paper is mainly about the re-design of airline seats's system for better ergonomics and Human-Computer Interaction. To face this change in the development of the seat system, there's a lot of new need of the HCI design of the new tech seat system. The different companies in the world start to make HCI design of the new seat system already. [1] Google and Microsoft and other USA's companies focus on the HCI based on the tech. Japanese companies focus on the tech \& culture behind the design.

Technology has a rapid development in the field of aircraft seats and seating systems, but the airline company hasn't developed the seat in 7-10 years because the US Federal Aviation Administration (FAA) of the head injury criterion (HIC) is strict expensive and complex to take a long time, the test is when aircraft emergency landing or the situation which plane couldn't take off, passenger's head should not being much of an impact by the redesign of the seat system. Its program is to ensure that passengers can survive (and preferably stay awake), so passengers can promptly fled away from the accident. The face is a fragile part of the body when it hit the screen, which will reduce the chances of passenger's escape. [2]

Some passengers have complaints about the discomfort of the seat's system offered by some airline company. They think the HCI and ergonomics of the seat system is outdated for a long time. So the designers should carry out a series of re-optimized design in ergonomics and HCI. this thesis describe a redesigned system based on research of the new tech and interactive. The design I propose is based on the User's Centered Design. This re-design of passenger seats for the use in the aircrafts or other tech seat systems fulfills the following needs: Comfort, Optimizing passenger's space, Functionality of IFE (In Flight Entertainment). This paper will focus on the following research areas: Aesthetics, Ergonomics, Innovation, Functionality, Weight, Interaction. 


\subsection{Design goal}

Problem: The HCI of an intelligence tech seat system is not perfect.

The main users of this problem: Middle-aged mid-range business aircraft users and private car drivers.

Problems scenarios: People in the car or airplane with a variety of interactive action generated when operating new technology tools.

Design tasks: the aesthetics and visual modeling for people to receive visual information, the ergonomics part for person to receive tactile information, new user's action innovation for people to receive and output information, the redesign of the structure of the system with low weight and cost, the functional system environment for people to receive information from human through movement in multiple environment.

\section{Design concept}

To achieve this complex design goal, there's the mind mapping of the design process, and to make more interesting design, there's some sketches of the design concept to make it more useful.

The things for design is concluded in several following parts after the mind storm: Redesigned ergonomics and HCI in original seat's systems, the aesthetics and visual modeling for people to receive visual information, the ergonomics part for person to receive tactile information, [3] new user's action innovation for people to receive and output information, the redesign of the structure of the system with low weight and cost, the functional system environment for people to receive information from human through movement in multiple environment.

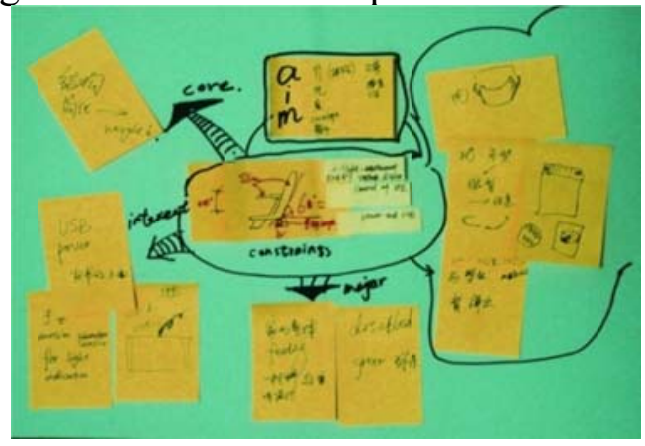

Fig. 1. Mind mapping

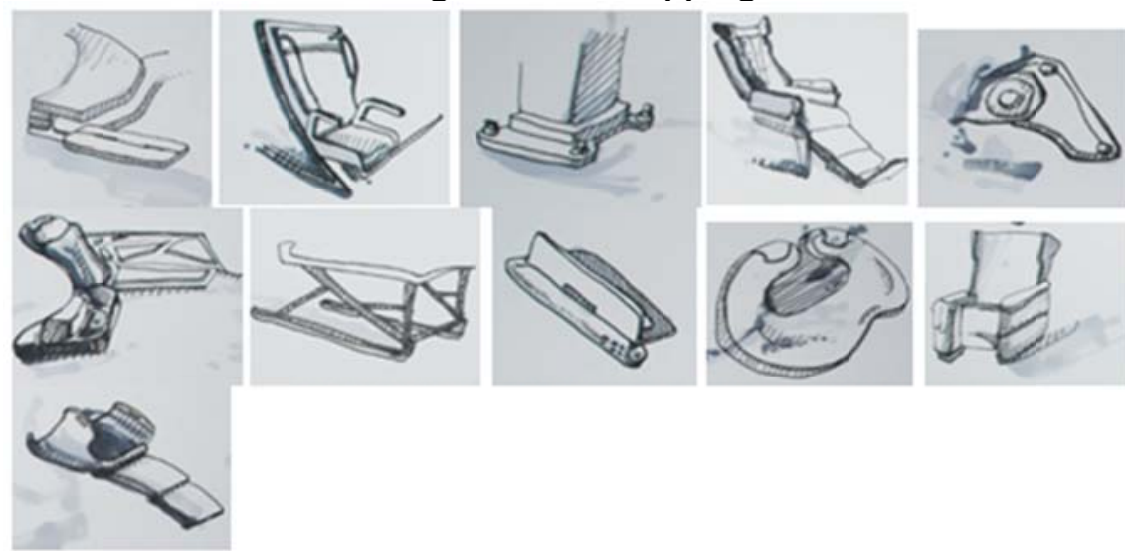

Fig. 2. Sketches of the design concept

\section{Aesthetic - formal \& visual transmission of information from humans}

The first step to make the seat system better after concept thinking is to make the formal and visual transmission of the information from humans better in the using of the seat system.

\subsection{Design composition and curve coordination}

The aesthetic design of the seat system based on a famous artist's, Kandinsky's theory. The shape of the products need to be comfortable and calmly when people see them. To put the point 
and line's constitution in a great reconstruction of the product will achieve the design goal.

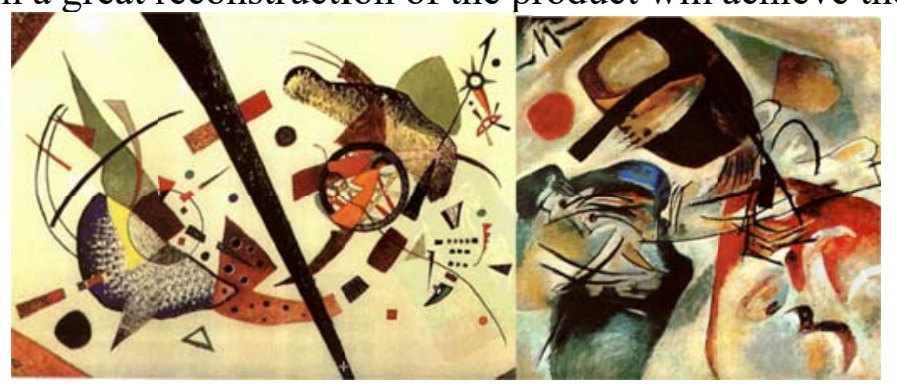

Fig. 3. Kandinsky, Kandinsky's Study of point line and surface, Russia, 2003, ISBN 9787300048918, Page 61-62[7]
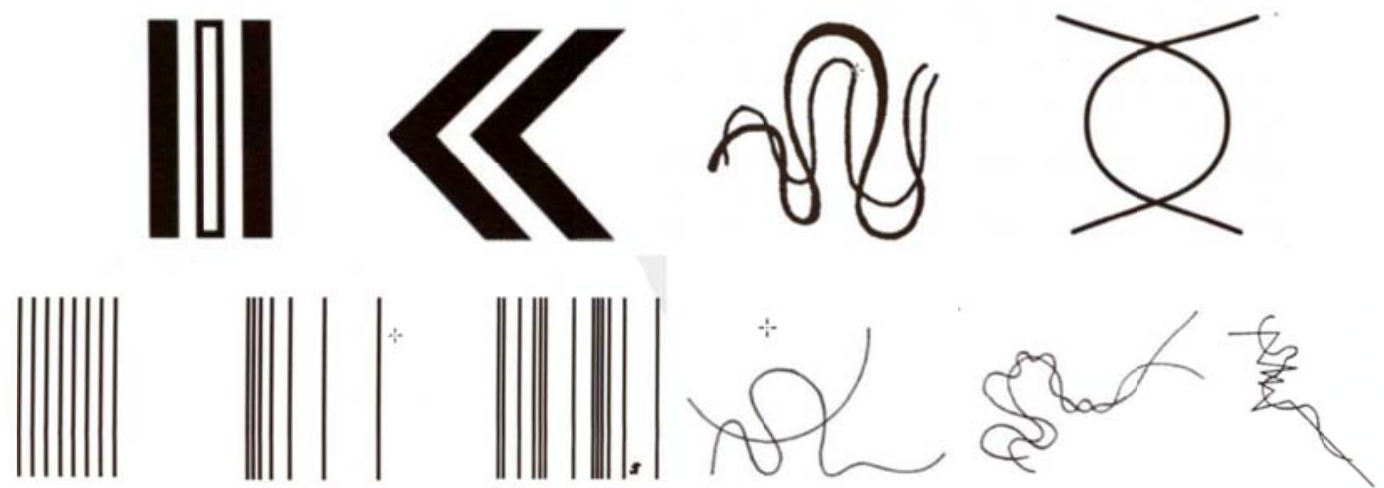

Fig. 4. Kandinsky, Kandinsky's Study of point line and surface, Russia, 2003, ISBN 9787300048918, Page 62-63[8]

The easiest design scene is repeated equally spaced straight lines exactly, the basic rhythm, or minute interval times, or repeated at intervals ranging on.

First, the first iteration aimed at increasing the amount of repetition, as pictures of the scene. If you rely on a lot of violin music play to enhance the sound of the violin.

The second iteration except that the amount of enhancement, there is sense of quality in music generally similar to repeat the same section of music after a long pause. [9]

The design is based on the thinking of Kandinsky, to make the shape of the seat system in a great design composition and curve coordination.

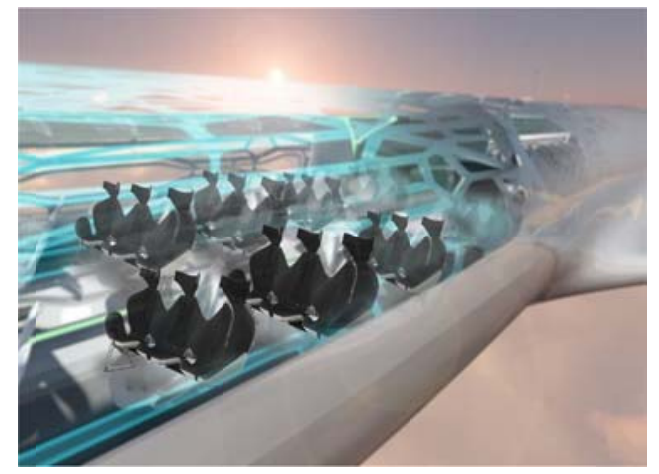

Fig. 5. Three-D Modeling design

\subsection{Design Semantics}

Based on the reconstruction of the seat system. The structure is generally inspired from the daily lives; eggshell. Eggshell is an important structure for the embryo. [10] Firstly, it forms a secured embryonic chamber for the developing embryo. Secondly, it provides a mechanical protection and controlled gas medium. 


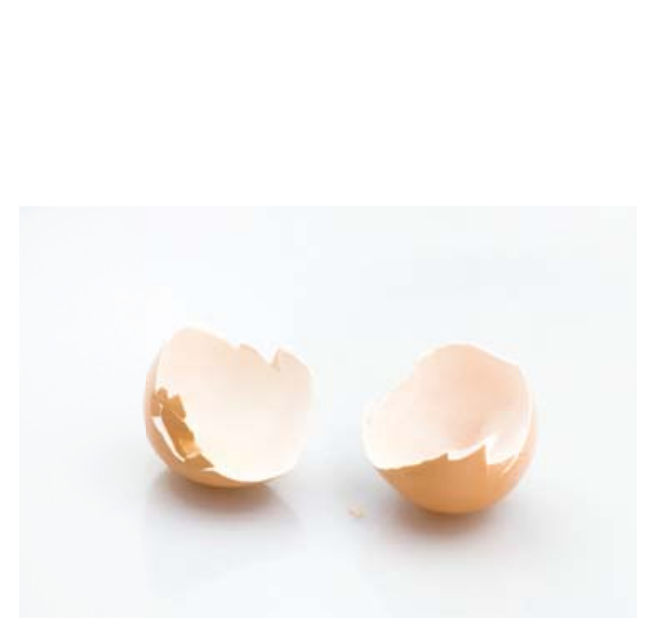

Fig. 6. Eggshell

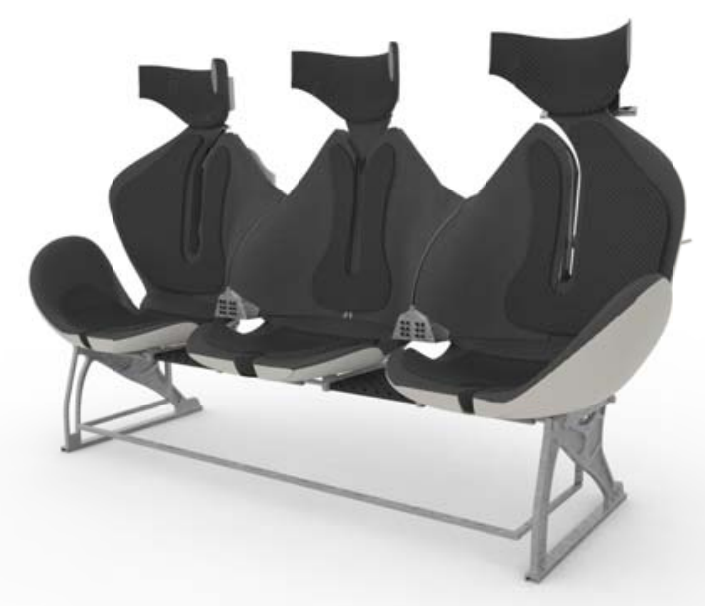

Fig. 7. Eggshell inspired design

The design strategy is to stimulate a cozy environment and protected structure just like the embryo, giving the passenger the most secured and comfy feeling for the rest of the journey.

As such, the re-designed model, adding more elements of modernized styles and to engage more with the passenger.

Color: Contrasting colors forms the basis of modern design. Meanwhile small details such as the handles have a combination of black and white to add on the element of mystery without being so boring. In artistic terms, this is known as the penetration of point, line and plane.

Shape: Eggshell is one of the most natural, beautiful and secured structure. We use ergonomics factors to define the main space of the seat as well as using passengers' behavior as one of our factors in making decisions.

The seat handles are different from the traditional on, for not only do they cater to the shape and moving actions of our arms, but they are also able to change in shape. The cushion, redesign to stimulate a circle form known as "Yin-Yang" provides an element of traditionalism.

The back rest is also a combination of aesthetic and ergonomics by providing the best of both worlds, in terms of passengers' comfort and space.

Hollow Spaces: Through research, we optimize the area of backseat to cater to the main pressure points. Thus, we decided to make the back rest and seat bottom hollow. [11]This does not reduce the strength and stiffness of the material but reduce the material costs. Furthermore, we design the cut in such a way that not only does it look aesthetically stunning; it is able to outlined the shape of the body and allow the passengers to feel as one with the spaces.

Crafts: Designers are born from craftsman. Thus, we incorporate the act of crafting when designing. We have read through many design references about molding and material books for crafting as we want to search for the easiest and most cost efficient way for producing it.

The result is that the most efficient way is to piece up different parts together like a Lego set. This repetitive process makes it fast and easy for factories to produce and easier for aircraft servants to clean it. Furthermore, black surface of the cushion makes it easier to maintain from dirt.

All in all, the shape of an egg provides an integral feeling; beautiful in and out, full of inspiration of modern internationalism design.

\section{Ergonomics—-sensorial transmission of information from humans}

After the aesthetic design of the seat system, the sensorial transmission of the information from humans need to be better designed. The ergonomics design based on analyzing the body position and pressure points on a human body when it is subjected to prolonged seating. in panel (a). Some spikes appeared in panels indicate body msovements as subject is rolling over during sleep. Furthermore, looking at the enlarged panels (b)-(d), they are clearly composed of the expected cardiorespiratory signals such as heart rates, respiration and body movements although the sensor's 
outputs have different performances at different time. Specifically, for extracting the proposed cardiorespiratory information from the original signals, some adaptive data processing algorithms both for PVDF film sensor and for conductive fabric sensor should be considered and developed. Simple and powerful data processing algorithms according to cardiorespiratory information to extract from PVDF sensor output and conductive fabric sensor output are therefore described and testified in following.

Table 1: The pressure distribution on the backrest surface[4]

\begin{tabular}{|c|c|c|c|c|c|c|c|c|}
\hline & \multicolumn{2}{|c|}{ No lumbar pillow } & \multicolumn{2}{c|}{ Small lumbar pillow } & \multicolumn{2}{c|}{$\begin{array}{c}\text { Middle lumbar } \\
\text { pillow }\end{array}$} & \multicolumn{2}{c|}{ Large lumbar pillow } \\
\cline { 2 - 9 } & $\mu$ & $\begin{array}{c}\mathrm{SD}(\mathrm{N}=6 \\
)\end{array}$ & $\mu$ & $\mathrm{SD}(\mathrm{N}=6)$ & $\mu$ & $\begin{array}{c}\mathrm{SD}(\mathrm{N}=6 \\
)\end{array}$ & $\mu$ & $\mathrm{SD}(\mathrm{N}=6)$ \\
\hline Weight/kg & 13.95 & 8.7 & 15.7 & 9.41 & 16.53 & 8.74 & 17.00 & 9.59 \\
\hline Surface/ $\mathrm{cm}^{2}$ & 994.4 & 143.5 & 1180 & 154.9 & 1249.4 & 134.5 & 1246.9 & 135.6 \\
\hline Pressure/ $\mathrm{kPa}$ & 1.34 & 0.64 & 1.28 & 0.59 & 1.28 & 0.53 & 1.32 & 0.58 \\
\hline Maximum/ $\mathrm{kPa}$ & 3.28 & 1.04 & 3.33 & 1.04 & 3.28 & 0.81 & 3.56 & 1.18 \\
\hline Slope/ & 0.26 & 0.05 & 0.30 & 0.06 & 0.28 & 0.04 & 0.29 & 0.05 \\
\hline $\begin{array}{c}\text { Maximum } \\
\text { slope/ }\end{array}$ & 1.63 & 0.33 & 2.12 & 0.60 & 2.25 & 0.29 & 2.18 & 0.82 \\
\hline
\end{tabular}

Table 2: Correlativity between subjective and objective evaluation results[5]

\begin{tabular}{|c|c|c|c|c|c|c|}
\hline & Weight/kg & Surface/cm & Pressure/ $\mathrm{kPa}$ & $\begin{array}{c}\text { Maximum/ } \\
\mathrm{kPa}\end{array}$ & Slope/ & $\begin{array}{c}\text { Maximum } \\
\text { slope/ }\end{array}$ \\
\hline $\begin{array}{c}\text { Lumbar } \\
\text { comfort }\end{array}$ & 0.679 & 0.661 & -0.227 & 0.196 & 0.022 & 0.613 \\
\hline Back comfort & 0.982 & 0.971 & -0.514 & 0.536 & 0.58 & 0.934 \\
\hline $\begin{array}{c}\text { Shoulder } \\
\text { comfort }\end{array}$ & 0.864 & 0.933 & 0.855 & 0.326 & 0.922 & 0.968 \\
\hline Neck comfort & 0.776 & 0.868 & 0.91 & 0.219 & 0.948 & 0.923 \\
\hline Total & 0.965 & 0.987 & -0.654 & 0.415 & 0.657 & 0.976 \\
\hline
\end{tabular}

From the above information, the product are able to analyse ideal seat height and area for construction and the support areas that should focus on as well as other information that should not neglect.

Firstly, the passenger's back will be in most comfortable position when it is not restricted to a given space. This is when the lumbar vertebra will be in a lordosis position*. As a result, the back and bottom of the seat should be strong enough to support the weight of the passenger.

An adult's lumbar vertebra point force point is about $23 \mathrm{~cm}$ to $26 \mathrm{~cm}$ higher than the seat. Thus, following these measurements, the product should model the support to be higher than the force point so that it is strong enough to support the back when the passenger laid back.

The two most important points should also be placed on shoulder rest and lumbar rest. However, most of the time, lumbar is the dominant part that exerts the force. Back rest can be ranged from $48 \mathrm{~cm}$ to $63 \mathrm{~cm}$ in width and $35 \mathrm{~cm}$ to $48 \mathrm{~cm}$ in height.

Secondly, when the passenger is seated, only a small part of the bottom is in contact with the seat surface. After our detailed calculations, it can be found that nearly $75 \%$ of the weight is supported by $25 \mathrm{~cm} 2$ of this contact area without a cushion. Not only will this cause a huge pressure exerted on 
our back, leading to soreness in our backbone area, it will cause sharp pain and aches after prolonged sitting. Adding a cushion will greatly decrease the pressure exerted on the back, by increasing the contact surface. A cushion acts as a support for proper seating position. [12]

Lastly, from our vivid observation and surveying, it has found that passengers will not remain rigid in their seating position for a long time. Thus, to optimize our use of material, it will be more logical and cost efficient to reduce the amount of material used in the construction of seat back, while not forgetting to maintain the comfort of the passenger throughout the flight journey.

\subsection{Size of seats}

Based on the research, it acquire the dimensions of seating position of both genders so as to maximise the comfort the majority of our passengers.

Table 3: Optimal adjustable range[6]

\begin{tabular}{|c|c|c|c|c|}
\hline \multirow{2}{*}{ Area } & \multicolumn{2}{|c|}{ Male } & \multicolumn{2}{c|}{ Female } \\
\cline { 2 - 5 } & $\mathrm{Lx} / \mathrm{mm}$ & $\theta /$ degree & Lx/mm & $\theta /$ degree \\
\hline $\begin{array}{c}\text { Neck and } \\
\text { shoulders }\end{array}$ & $670-770$ & $10-20$ & $570-620$ & $10-15$ \\
\hline Upper limb & $570-670$ & $5-20$ & $570-620$ & $0-15$ \\
\hline Truck & $620-720$ & $10-20$ & $570-620$ & $10-20$ \\
\hline Lower limb & $670-770$ & $5-20$ & $620-670$ & $5-20$ \\
\hline Operating gear & $620-670$ & $0-10$ & $570-620$ & $0-15$ \\
\hline
\end{tabular}

Lordosis is the inward curvature of a portion of the lumbar and cervical vertebral column

This data forms the basis to our modelling work as our requirement is to fulfil the criteria of population, taking $50 \%$ of the passengers as men. The following takes the 50th percentile of each data:

Table 4: 50th percentile of data in Table 3[13]

\begin{tabular}{|c|c|c|}
\hline Area & Lx/mm & $\theta /$ degree \\
\hline Neck and shoulders & $620-695$ & $10-12.5$ \\
\hline Upper limb & $570-645$ & $2.5-12.5$ \\
\hline Truck & $595-670$ & $10-20$ \\
\hline Lower limb & $645-720$ & $5-20$ \\
\hline Operating gear & $595-645$ & $0-12.5$ \\
\hline
\end{tabular}

Conclusion:

Cushion area: ischium endures the largest pressure which decreases gradually as it spreads out; the smallest pressure is supplied by the thighs.

Back rest can be ranged from $48 \mathrm{~cm}$ to $63 \mathrm{~cm}$ in width and $35 \mathrm{~cm}$ to $48 \mathrm{~cm}$ in height: shoulder blade and lumbar vertebra are two main supporting points and pressure gradually reduces outwards along the two points.

The right and the left back seat experience the same pressure.

The seat should suit the shapes of back, legs and the bottom of thighs.

Two supporting points: one is between the fifth and sixth thoracic vertebras; the other is on the waist.

\section{Interaction-transmission \& reception of information from humans through movement}

To make the system have a cleverer HCI and make it more useful, the design makes the system 
good in both ergonomics and HCI. The new tech influences our life a lot nowadays. Inside a conference room at Google's San Francisco office, there's a screen in front of the displaying raw output data from a tiny sensor just below one's hand. If someone moves the thumb up and down against the finger, at first quickly and then almost imperceptibly. Each time, the blue dot on the screen moves along with the finger. [14] It can be flipped to a new demo, and now it is being made a circle with the thumb. The faster thumb goes, the faster the blue dot spins.

It's a tiny chip, one will soon be remarkably easy to add to nearly any device: inside the frame of a VR helmet, the bezel of a smart watch, the chassis of your phone.[15]

The way when swipe a touchscreen, twist a knob on the stereo, or scroll the finger around the iPod's touch wheel. With the right tracking system, it could be flipped a light switch without the switch, or turn up the volume on the speakers without actually touching them just by sliding the finger. The gestures don't have to be huge and exaggerated: it don't need to wave like a madman in front of the Kinect. [16] They can be as small as they are in real life.

Right now, it says that the gesture technology has depended on exaggeration. Camera-based systems, like Leap Motion or Intel's Real Sense, are big and slow, and can't see through walls or at night. Capacitive sensors are great for touch, but not seeing in three dimensions; when it cross the fingers they fall apart.

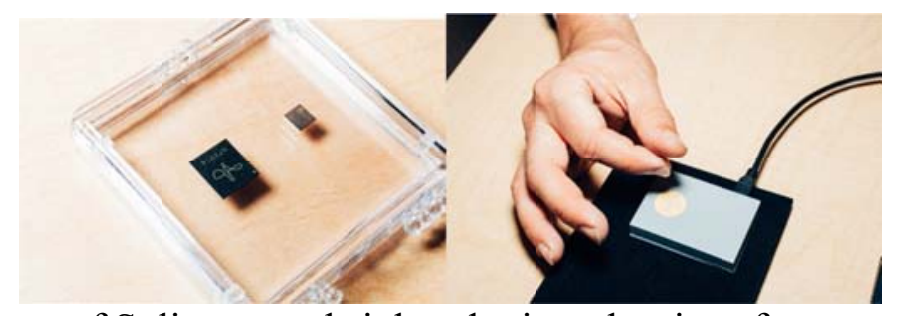

Fig. 8. The challenge of Soli was to shrink radar into the size of a computer chip. PETER MCCOLLOUGH FOR WIRED

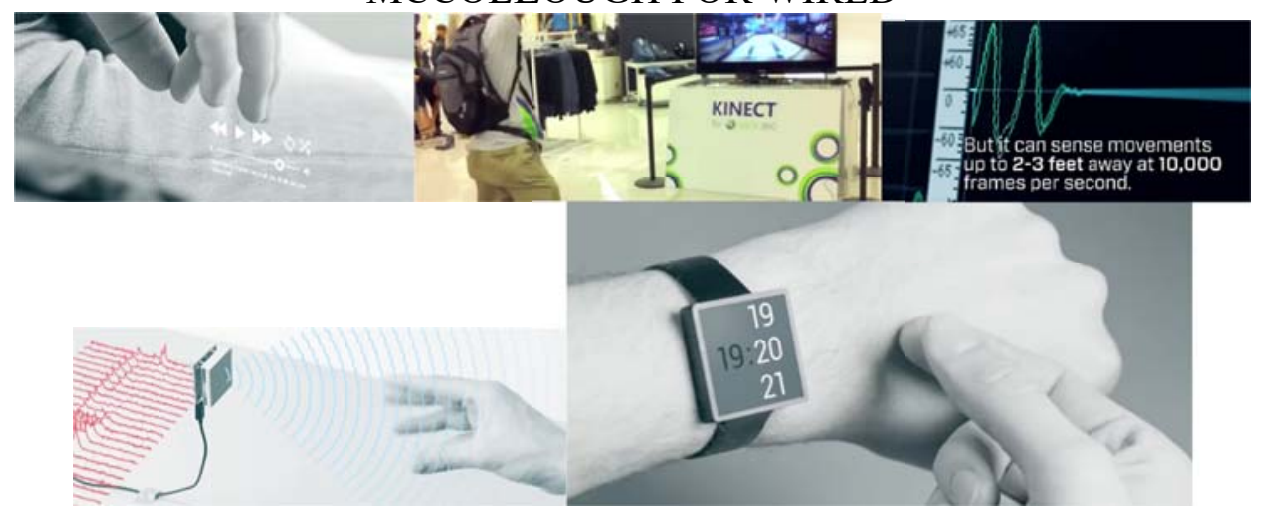

Fig. 9. New tech in google[16]

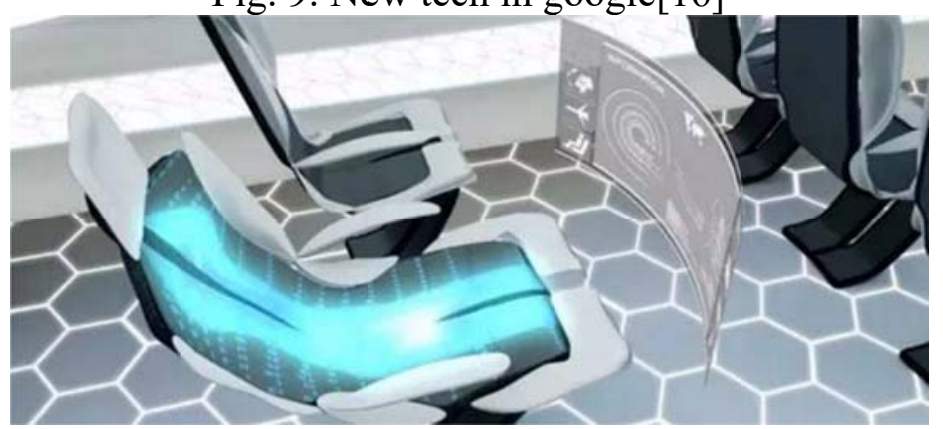

Fig. 10. The sensor in the seat system can be directly used for the interaction of the hand moving.

[16]

\section{Structure\&Weight\&Cost—reception of information from human through movement in single environment}

The another part of the design is the structure and weight and the cost of the seat systems.

\subsection{Structural Mechanics}


Based on patent analyses, the product is able to do a close comparison with its own design and modify the current design to suit our needs. The following designs illustrate our points to improve the strength of existing seat skeleton structures:

Hollow tubular structure should be one piece, without any external components such as screws. Similarly, when constructing a house, each house pillar must be one piece and not segmented into different components as a shift in one of the component will cause the whole house to collapse. [17]
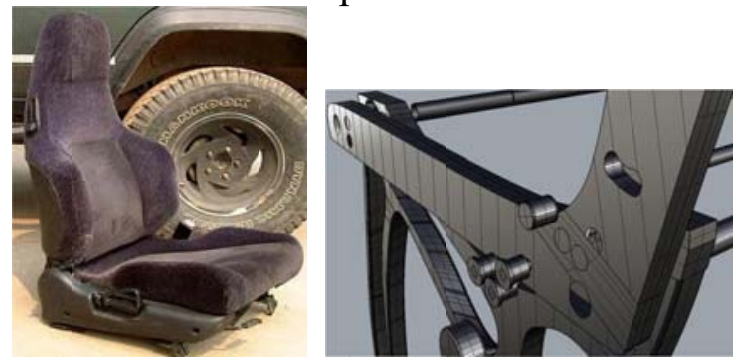

Fig. 11. Simple structure and redesign[18]

Supporting planar plate with semi hollow cut will allow the whole structure to endure about the same stress through shear formation.

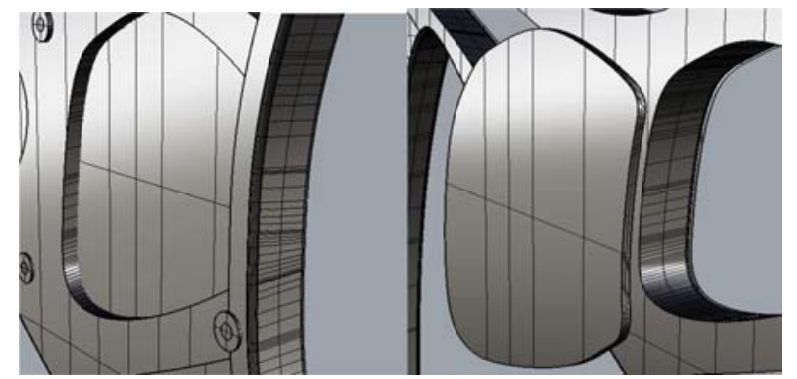

Fig. 12. Redesigned structure

Adding additional support components such as screws to one piece components helps to increase the 3D shear forces at predicted weakest areas.

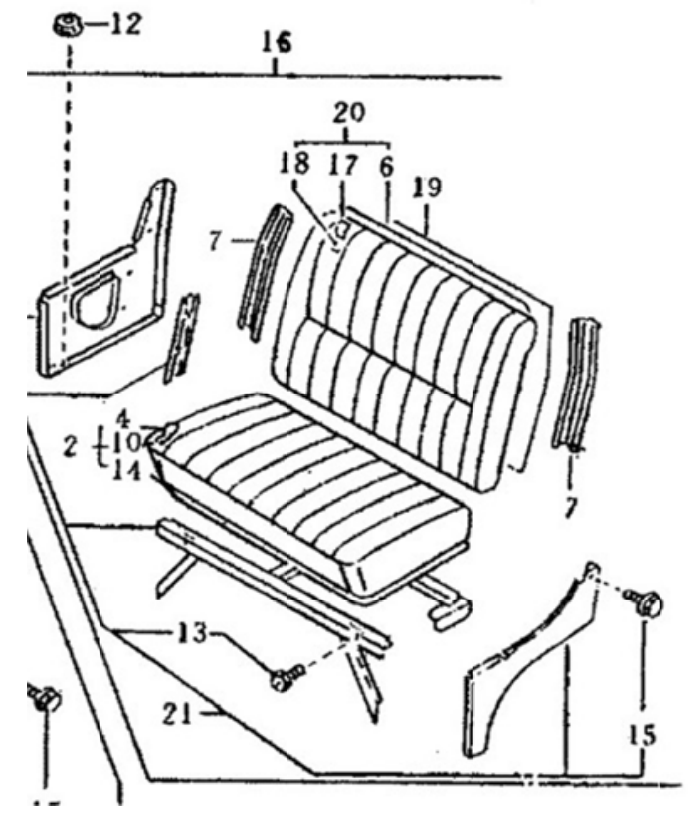

Fig. 13. Simple structure [20]

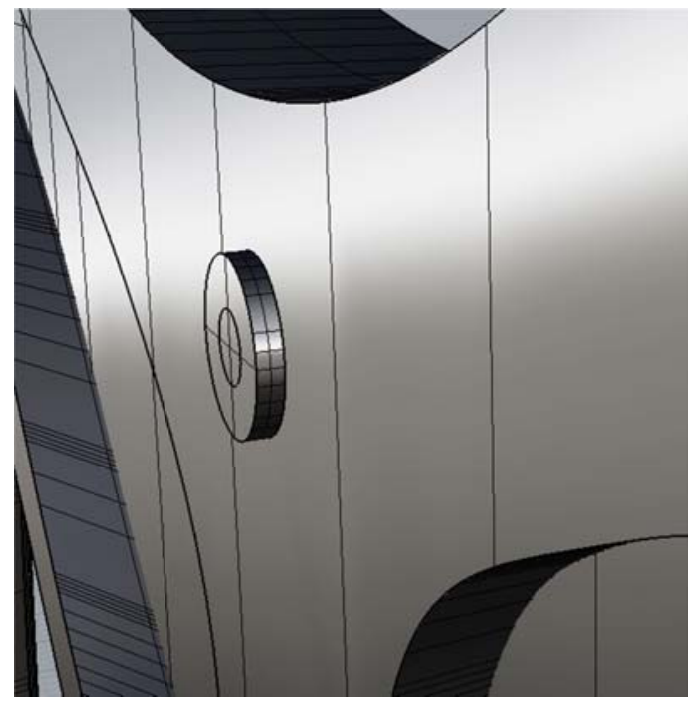

Fig. 14. redesigned structure

Spider-shaped seat bottom bifurcation is to spread out the center of gravity and distribute it to a larger area, thereby reducing the amount the force per unit area. However, it must be soldered to ground to ensure stability.[21] 


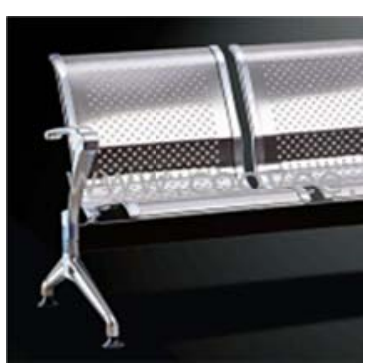

Fig. 15. Simple structure [22]

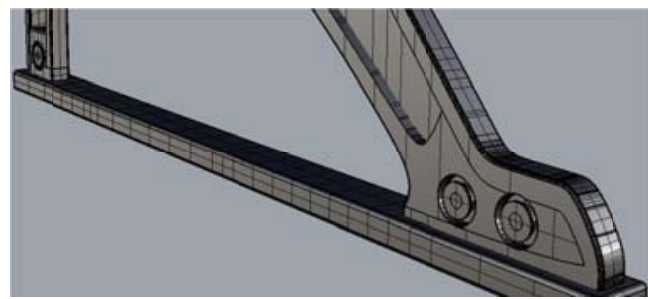

Fig. 16. redesigned structure

Pillars of each arch bend (or triangular) is to maximise the force that it can support. Patent US4375300 has also proven that triangular hinge is the best structure to support maximum truss [23]

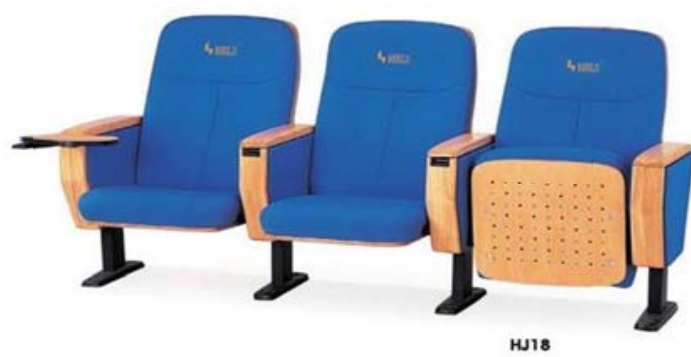

Fig. 17. Simple structure [24]

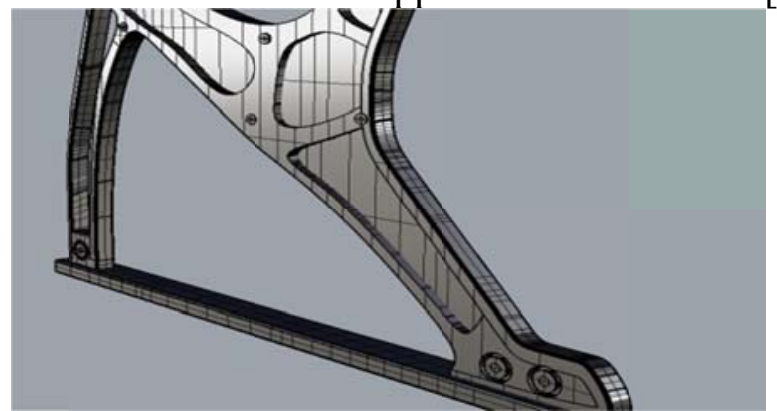

Fig. 18. redesigned structure

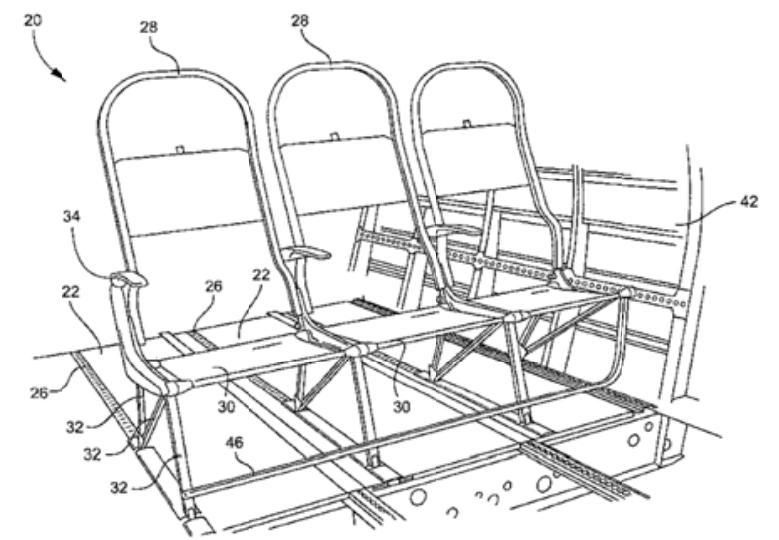

Fig. 19. US8544796 B2 Skeletal Structure of Seat [25]

Traditional Airline Seat Skeleton has 2 support points, mainly on the ends of each side, with small hinges to support a large skeletal structure. [5]

The redesign is completely opposite of the above concept. It focuses on minimising the area of skeletal structure for a larger support area. Not only does it reduce the weight of the support, we can also provide a safer seat structure. This is through maximising the support area to a long beam connecting all the chairs so that can equally distribute the pressure by the passenger to a greater area. 


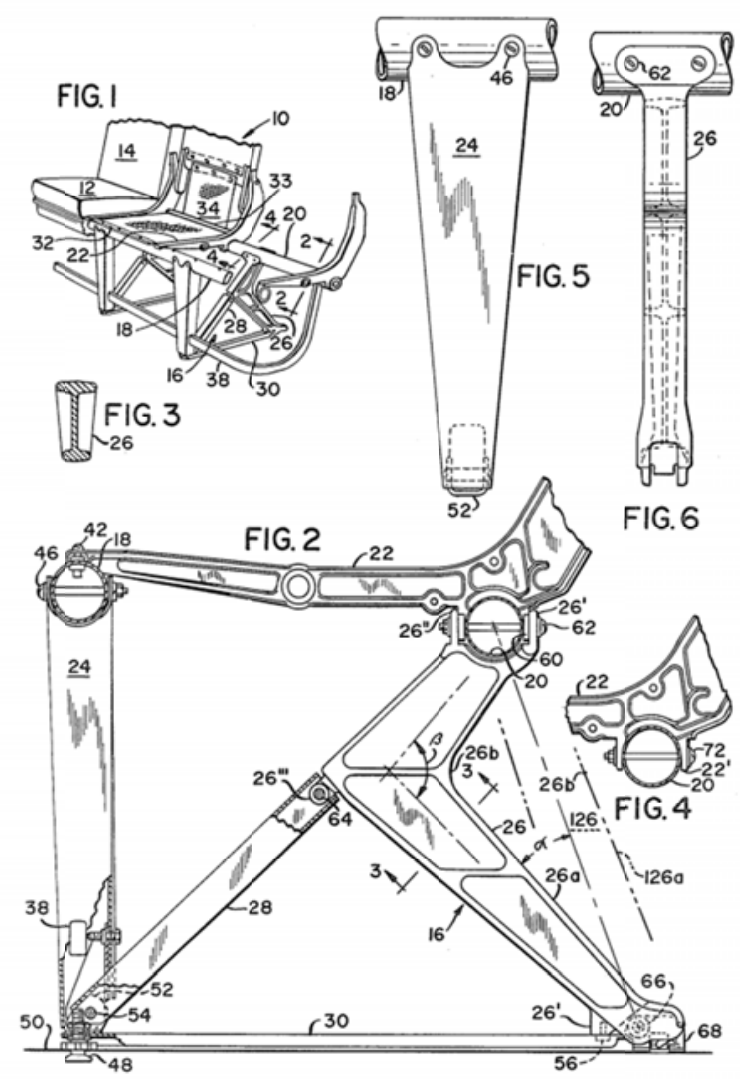

Fig. 20. US4375300 Strong Triangular Support Structure US4375300 Strong Triangular Support Structure [26]

By changing the traditional support leg base to a stent-like support, not only does it not affect the amount of weight it can carry, it reduces amount of material used, and give passengers more space allowance.

\subsection{Material Mechanics}

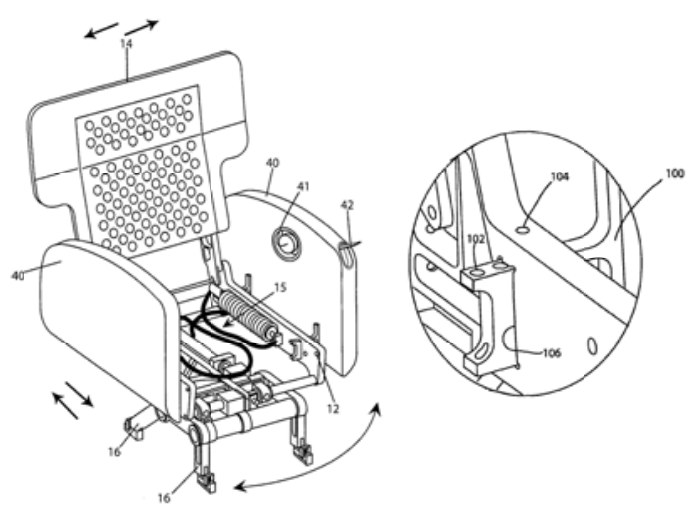

Fig. 21. US8376462 B2 Aircraft seat with adjustable armrests US8376462 B2 Aircraft seat with adjustable armrests [27]

Air holes to minimise volume of material used, yet strength does not differ much. It minimizes usage of materials thus saving cost. More holes are designed to be placed on back support than seat support as the main pressure point is on the lower seat area. 


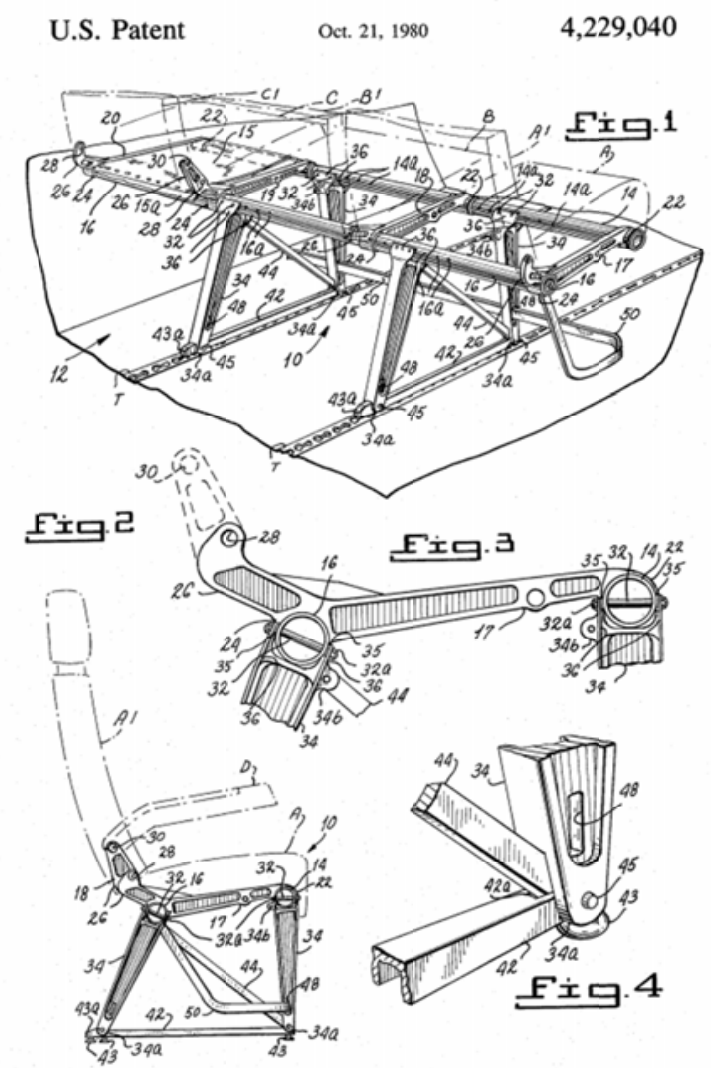

Fig. 22. US4229040 Triangular Support saves cost and materials US4229040 Triangular Support saves cost and materials[28]

Oblique Triangle and hollow tubular structure provides about the same force as solid structure without changing the comfort of the passenger in the movable mechanism. It reduces the amount of material used hence the size and weight of the entire structure.

\subsection{Weight}

Structural Mechanics

Cutting down on materials in unnecessary areas is necessary to save on material costs while providing about equal pressure support. Most importantly, weight of the heaviest part of the structure is reduced.
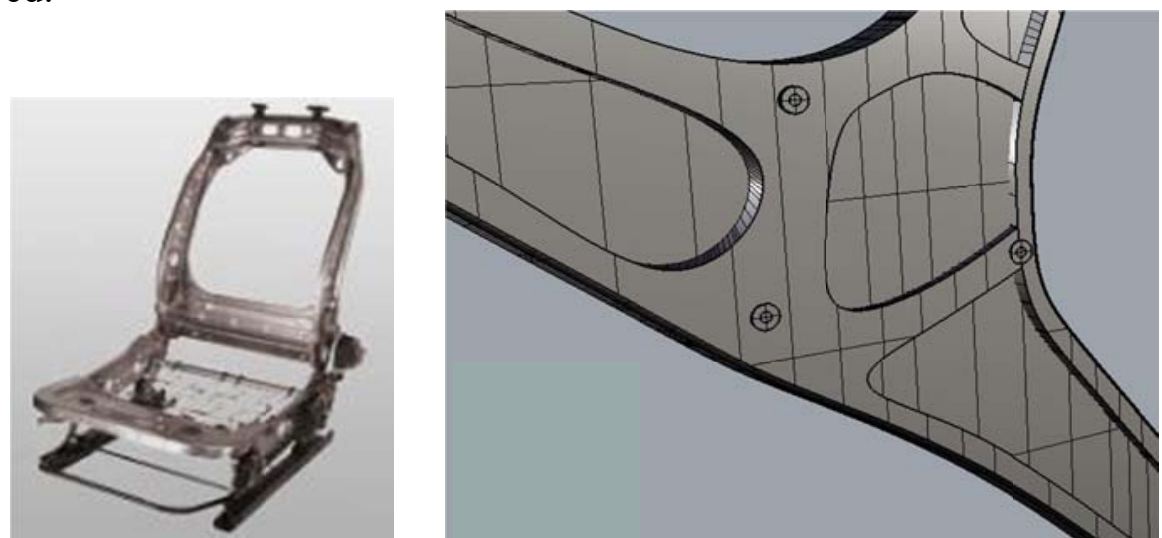

Fig. 23. simple seats Fig. 24. simple seats

Material Mechanics 


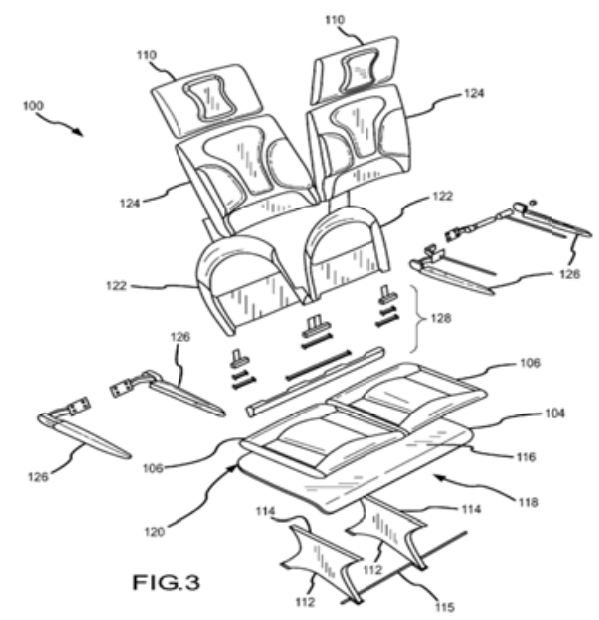

Fig. 25. US007954762B2 light yet strong material US007954762B2 light yet strong material[29]

Aircraft utilizes composite materials to achieve significant weight savings relative to conventional seat designs. The seat assembly includes a lightweight composite support structure, a lightweight composite seat base, and a seat back assembly that employs a lightweight inner frame.

From this patent, one lesson to take away is that composite materials known as advanced polymer matrix composites is one of the area which can research more into to find the best material to construct the skeletal structure in terms of weight.
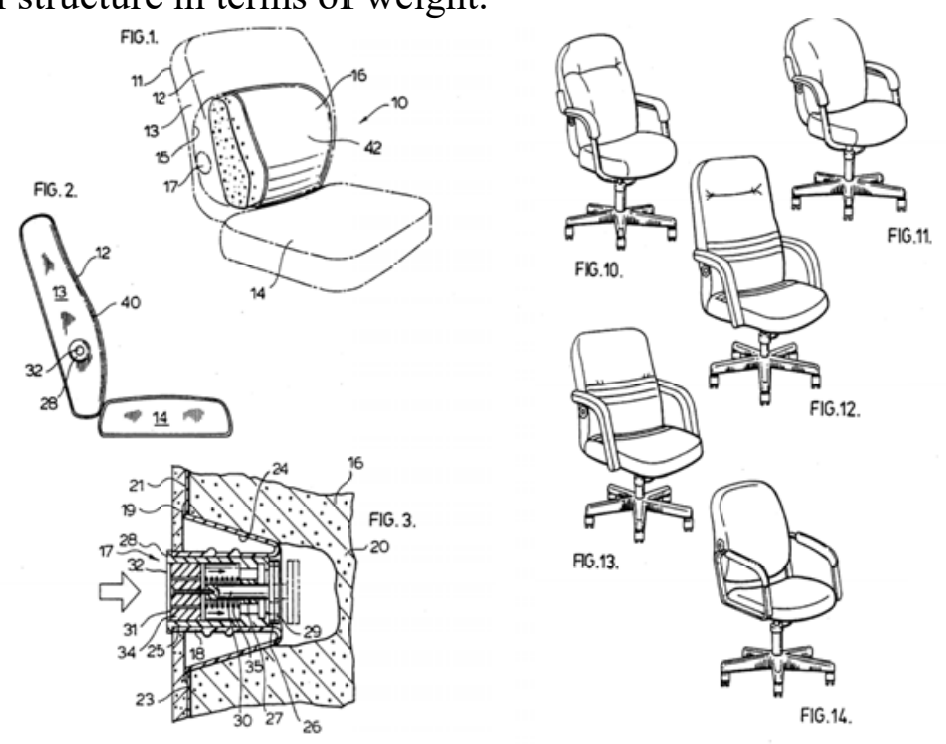

Fig. 26. US5660438 Seat Cushion US5660438 Seat Cushion[30]

Sponge foam cushion with air holes inside. Cushion shape changes according to the back shape of each user, maximizing comfort and minimizing materials used. (Personalization) Inflatable mattress variant degree has been calculated to ensure that the basic shape can provide ergonomic uses. [31] 


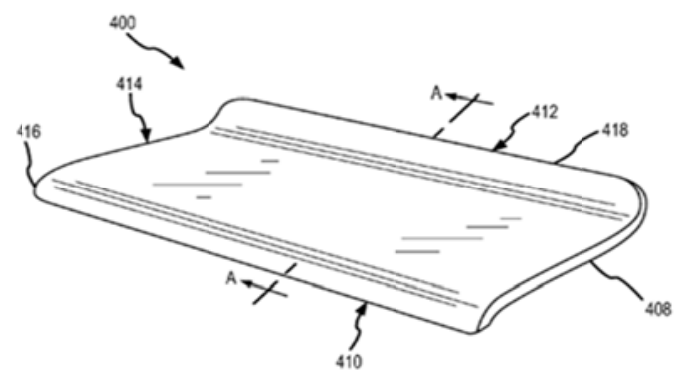

Fig. 27. US007954762B2 Carbon Fibre tube as metal structure US007954762B2 Carbon Fibre tube as metal structure[32]

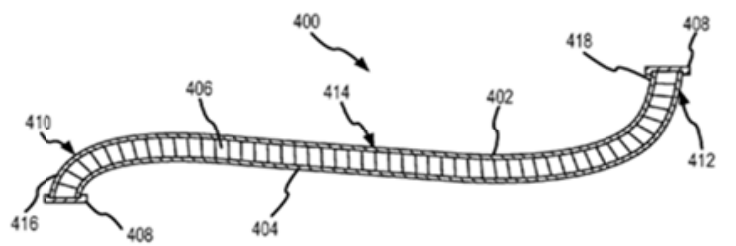

Fig. 28. US007954762B2 Carbon Fibre tube as metal structure[33]

Seat uses the support of carbon fibre tube, does not require additional metal support structure Upholstered carbon fibre tube support, cushion foam structure is constructed with half of the sponge (foam) in order to achieve a comfortable seating position, saving material.

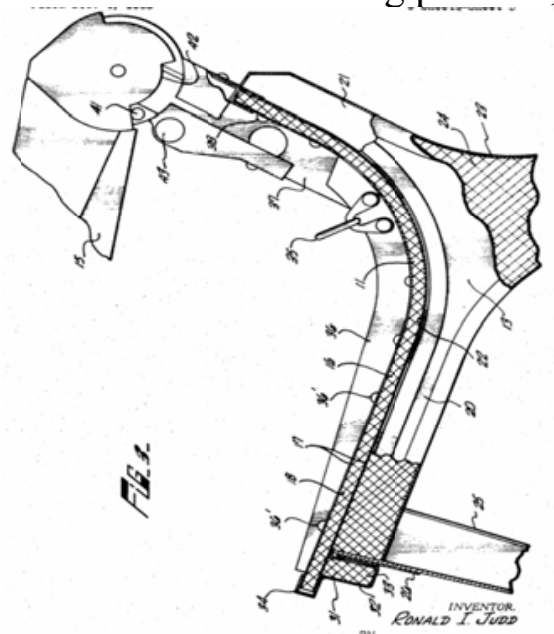

Fig. 29. US3468582 Honeycomb Structure US3468582 Honeycomb Structure[34] Honeycomb structure is able to reduce the weight of the seat yet provide the same comfort for users.

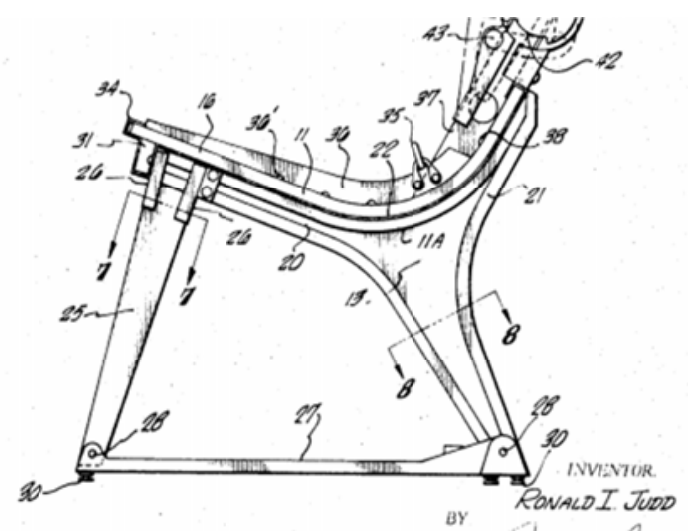

Fig. 30. US3468582 Honeycomb Structure 
Forward thigh support structure is higher than back seat support as it can provide more leg space for the users. Using Y shape support for the back structure (Honeycomb), it can also reduce the weight of the whole seat structure yet providing approximately the same weight support. [35]

From this, it concluded that honeycomb material reduces the total weight of support structure yet is able to support about the same pressure as original design. It is both light and strong.

\subsection{Cost}

Material Mechanics

By minimizing the usage of materials and selecting the most economical yet strongest material, we are able to reach the point of optimizing material cost. By removing unnecessary materials, it is able to reduce the cost. As shown in material and structural mechanics, it is able to reduce the material used without reducing much of the strength that the skeleton can support. The choice of materials for both the exterior and interior components will be further illustrated in the following sections.

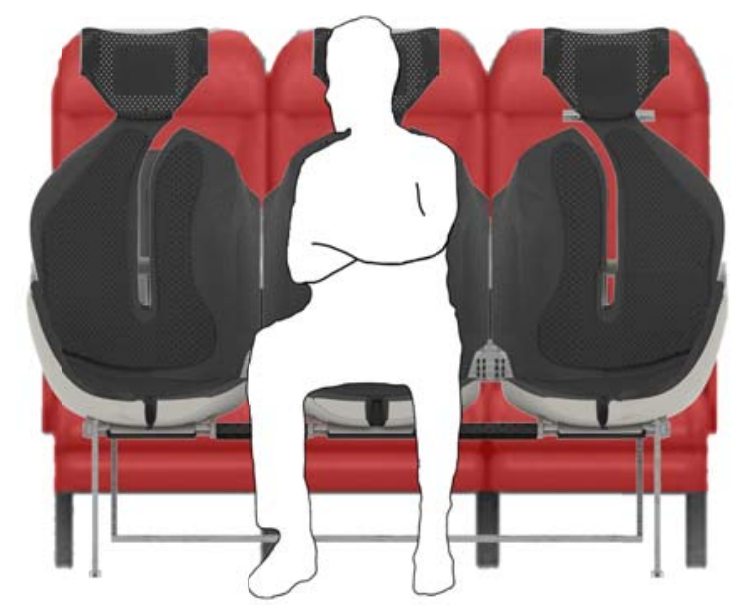

Structural Mechanics

Fig. 31. Material and Cost Saving New Design

On the structural side, by reducing the amount of area of the skeleton support, we can minimize both the material usage and minimize the cost. On the side note, we must not sacrifice the strength of support for the sake of minimizing material cost, as safety is a huge factor. Hence, by analysing all the possible patent designs in strength supports and modifying to our needs, we are able to create a stable low cost structure.

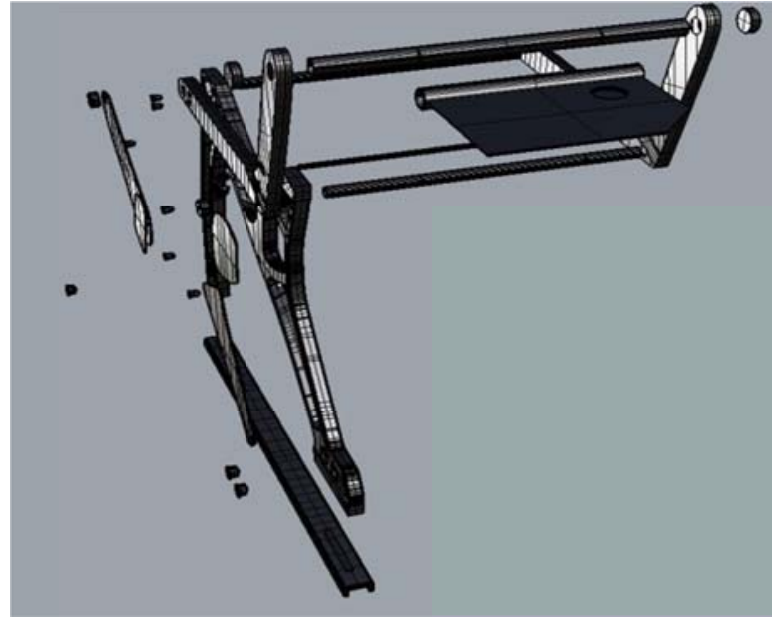

Fig. 32. Back Individual Components

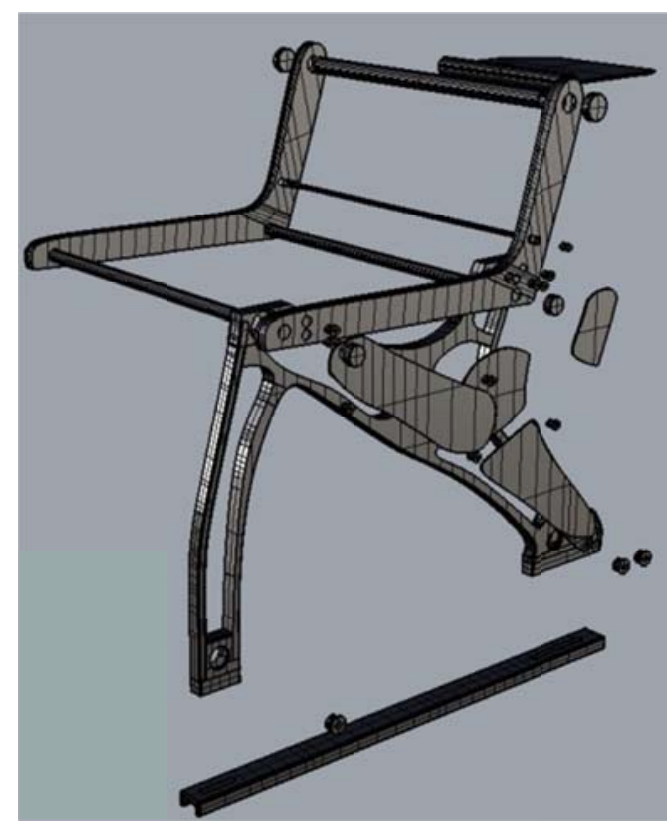

Fig. 33. Front Individdual Component 
Also, the new design let the seat system have more functionality through the movement of the human.

\section{Dimension of Seat Design}

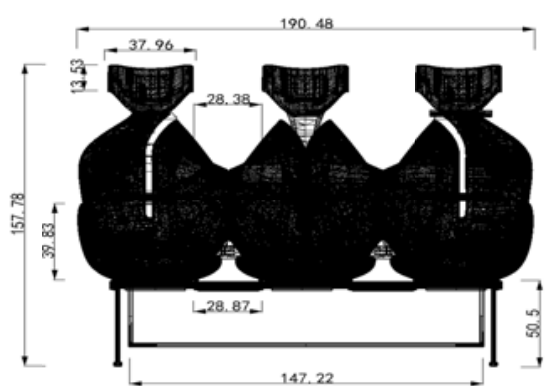

Fig. 34. Front Dimension

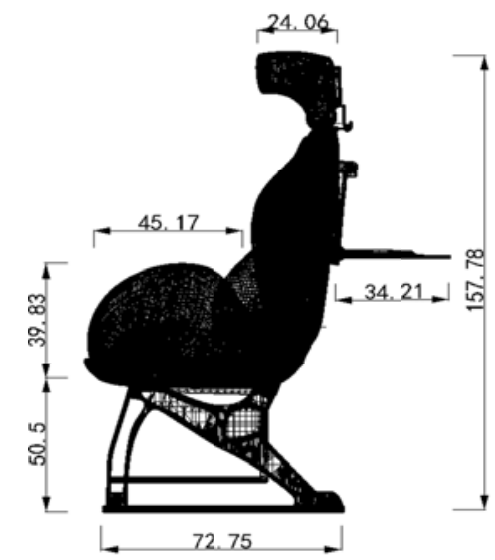

Fig. 35. Side Dimension
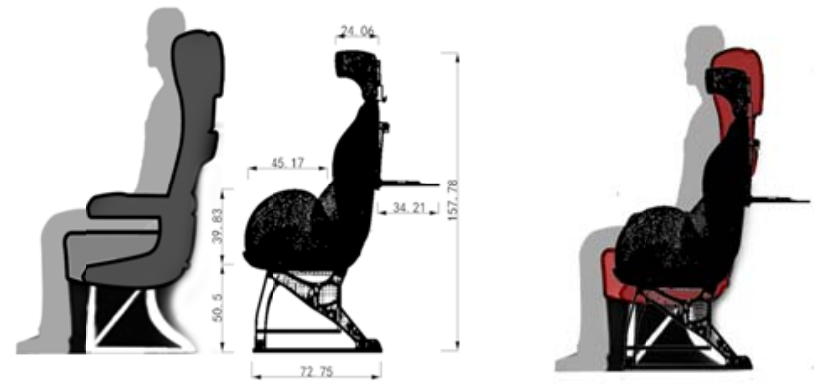

Fig. 36. Seat to Seat Dimension

Final Product Design


Fig. 37. Side View of Final Product

Fig. 38. Back View of Final Product 


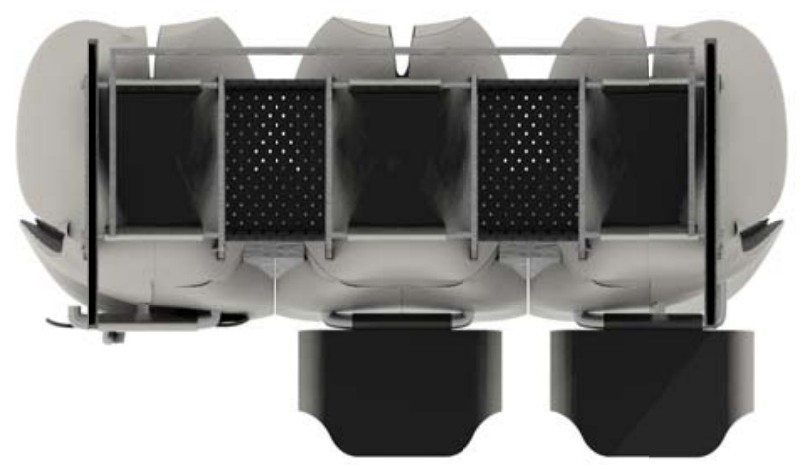

Fig. 39. Bottom View of Final Product

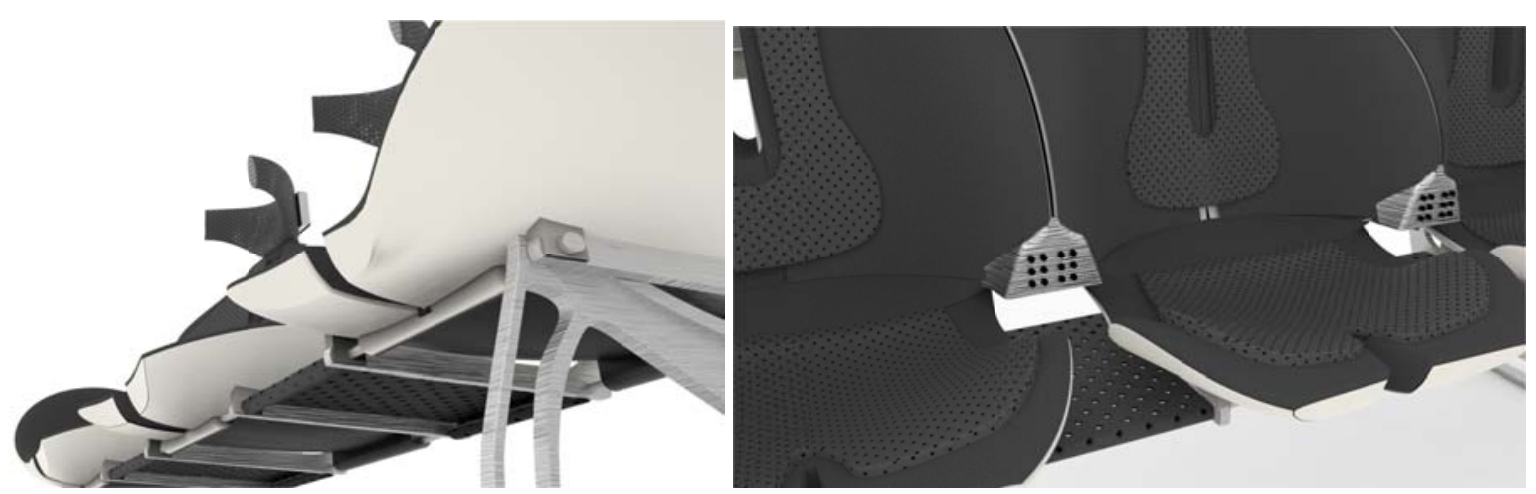

Fig. 40. Seat Cushion of Final Product

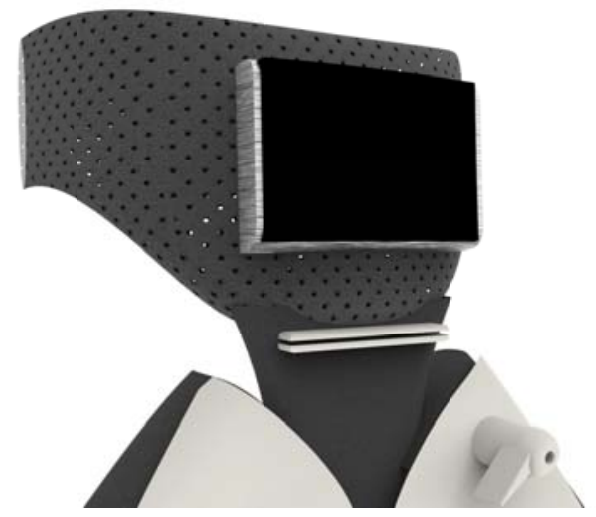

Fig. 41. IFE
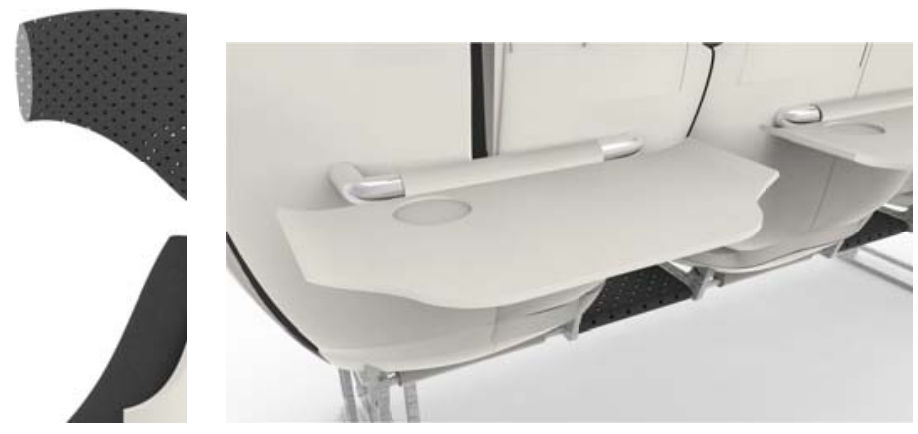

Fig. 42. Table Top

\section{Bibliography}

[1] Wickens Christopher, Human Performance Modeling: HP2 -- Using Empirical Research and Human Performance Modeling to Predict Astronaut Performance in Long-Duration Space Missions, Proceedings of the Human Factors and Ergonomics Society 2014 Annual Meeting 2014-10-27 p.834-838.

Christopher describes an effort to model and predict astronaut performance during sudden workload transitions in long duration missions. He approaches to the work is heavily based on empirical research. He has performed a set of meta-analyses 1) to identify the quantitative effects of poor sleep on task accuracy and task completion time, and 2) to develop a model of operator task selection during multitasking. He is currently developing a model, based on a literature review, to predict the effects of automation design factors on operator task performance.

I use Christopher 's opinion to operator performance during a workload transition for tech seat systems, it also help me describe the empirical and theoretical underpinnings of a model that predicts the effects of tech seat's performance. 
[2] Rosson, Mary Beth, Affective HCI and Emotions and Motivational Aspects, Proceedings of IFIP INTERACT'15: Human-Computer Interaction, Part I 2015-09-14 v.1 p.201-209.

Mary thinks as information systems become more integrated into everyday use, people generate and store significant data through their lifetimes. Only recently have researchers and companies started to pay attention to digital legacy issues. Google has been one of the first companies to support users in planning the future of their digital assets through Google Inactive Account Manager (IAM).

I use Mary's research to present several new interaction ways to improve the new tech seat systems with challenges regarding future impact of these decisions.

[3] Wright Peter ,Exploring Gesture Sinification to Support Reflective Craft Practice, What do I hear? Communicating with Sound, Proceedings of the ACM CHI'15 Conference on Human Factors in Computing Systems 2015-04-18 v.1 p.67-76

Peter thinks much of the knowing employed in skilled craft practice is difficult to communicate solely through written or verbal description. Consequently, the reflection and development of a craft practice in this manner may miss important nuances of practitioners' skills and experiences. We created digital technologies to signify (using audio to perceptualize data) a group of craft practitioners' gestures to explore how we can aid their reflection in and on their craft, and consequently develop it. Over a number of workshops, the design of these significations were iterated based on how the practitioners responded to them.

I use Peter's thinking to found that direct signification of gesture (sounds generated directly from motion sensor data) helped practitioners understand and reflect upon their own and each other's practice in the seat tech systems.

[4] Lee Da Hee, An Outlook for Content UX in TV: The Emergence of Augmented Content, Extended Abstracts of the ACM CHI'15 Conference on Human Factors in Computing Systems 2015-04-18 v.2 p.789-796

Hee describes the findings from our exploration on content user experience for next-generation live TV and VOD (Video-On-Demand) services. First, He introduce its background study on new trends in the TV industry. Based on this study, He list several keywords that characterize the content experience for next-generation TV. He then describes his interviews with six professionals working in content production. These interviews were conducted to verify our derived characteristics, and to collect the thoughts of these experts on the contribution of UX to future content production.

I learn from it and use Hee 's thinking which has a significant potential to provide content UX for next-generation television services in the new tech interaction.

[5] Kim Dongseok, User Situation-Aware Mobile Communication Method, HCI International 2015: 17th International Conference on HCI: Posters' Extended Abstracts, Part II 2015-08-02 v.5 p.508-513

Kim shows his thinking about communicating information through electrical mobile devices solely relies on static functions provided by the mobile devices. For example, when a caller uses the call function on a mobile device, the other caller at the receiving side has only two static functions to execute namely reject or answer. Under most of communication environment, the caller does not recognize the receiver's current context. In this paper, he proposes SCS (Situation-aware based on Communication Service) platform to provide an appropriate method to express useful information based on user context like speak-able, read-able, gesture-able situations through mobile devices.

I use his thinking with new useful information based on user context like speak-able, read-able, gesture-able situations through the tech seats system.

[6] Johnson Peter W, Differences in the three-dimensional typing forces between short and long travel keyboards, Proceedings of the Human Factors and Ergonomics Society 2014 Annual Meeting 2014-10-27 p.1447-1450

Johnson thinks about the keyboards with shorter key travel are becoming widespread yet it is unknown whether there are any biomechanical differences in the typing forces when using these keyboards. If one keyboard promotes typing with more force, this may increase the risk for developing an upper extremity disorder. A total of 17 subjects typed on two short travel keyboards $(<2.5 \mathrm{~mm})$ and one long travel keyboard $(4.0 \mathrm{~mm})$. The magnitude and angle of the typing forces 
were measured in the $\mathrm{x}-, \mathrm{y}$ - and z-axes using a thin, three-dimensional force platform. The aim of this study was to determine whether there were differences between the short and long travel keyboards in the magnitude and direction of the typing forces and the keystroke durations. In addition, we wanted to determine whether there were typing force differences between key rows, hands, and fingers. Keyboards with shorter key travel resulted in less extreme angles and smaller magnitudes for forces applied in the $\mathrm{x}$ and $\mathrm{y}$ directions. Shorter travel distances were associated with smaller peak and mean vector sum forces and shorter keystroke durations. Although these results indicate keyboards with shorter key travel affect typing biomechanics, it is uncertain whether the small differences in keystroke durations and applied typing forces are physiologically meaningful and would reduce a computer user's risk for developing an upper extremity musculoskeletal disorder.

I use his research to write the new tech interaction in the keyboards of the seat systems, and redesign the keyboards.

[7] Kandinsky, Kandinsky's Study of point line and surface, Russia, 2003, ISBN 9787300048918 , Page 61-62

[8] Kandinsky, Kandinsky's Study of point line and surface, Russia, 2003, ISBN 9787300048918 , Page 62-63

[9] Kandinsky, Kandinsky's Study of point line and surface, Russia, 2003, ISBN 9787300048918 , Page 61

[10] Association, T. E. (n.d.). Powder Metallurgy, Advantages and Reasons for Choosing the Powder Metallurgy Process.

[11] Association, T. E. (n.d.). Powder Metallurgy, Advantages and Reasons for Choosing the Powder Metallurgy Process.

[12] Baidu. (n.d.). Retrieved from Correlativity between subjective and objective evaluation results

[13] Chen, X, The Application and Finite Element Analysis of Magnesium Alloy on Automobile Seat Structures. 2007, China Academic Journal Electronic Publishing House

[14] EP0327170A2: Flame retardant composite polymeric foams. (n.d.).

[15] Association, T. E. (n.d.). Powder Metallurgy - Advantages and Reasons for Choosing the Powder Metallurgy Process.

[16]Baidu. (n.d.). Can Google Fix Gesture Tech With Tiny, All-Knowing Sensors?

[17] Chen, X, The Application and Finite Element Analysis of Magnesium Alloy on Automobile Seat Structures. 2007, China Academic Journal Electronic Publishing House.

[18] EP0327170A2: Flame retardant composite polymeric foams. (n.d.).

[19] F. Feng, J. H. (n.d.). The Design of Resistance to Fatigue Automobile Seat Based on Ergonomics. Mechanical Management and Development, Vol 25, No 3.

[20] Fei, F. (n.d.). A Study of the Relation between the Adjustable Dimensions of Automobile Seat and Driving Comfort. China Academic Journal Electronic Publishing House.

[21] J, W., H, H., X, L., L, Z., \& Y, T. (2011). Lightweight Design of Automotive. In Journal of Shanghai University of Engineering Science, Vol 26.

[22] Ling, L. (2012). Research on Subjective and Objective Evaluation Method of Automobile Seat Static Comfort Level. China Academic Journal Electronic Publishing House.

[23] MIYAZAKI, Y. (2003). Welding Methods and Forming Characteristics of Tailored Blanks (TBs).

[24] US3638255A: Seat cushion or pillow. (n.d.).

[25] Yang, T. (2012). Optimal Design on Structure and Forming Process for Lightweight of Automobile Seat.

[26] Yuan, S. (n.d.). On the comfort of car seat China Academic Journal Electronic Publishing House.

[27] Zou, B. (2009). The Design of Comfort of Automobile Seat Based on Ergonomics. Automobile Science and Technology, Vol 4.

[28] F. Feng, J. Hou. (N. A.) The Design of Resistance to Fatigue Automobile Seat Based on Ergonomics. Mechanical Management and Development, Vol 25, No 3, pp. 16-17 
[29] B. Zou. (2009) The Design of Comfort of Automobile Seat Based on Ergonomics. Automobile Science and Technology, Vol 4, pp. 15-17

[30] L. Ling. (2012) Research on Subjective and Objective Evaluation Method of Automobile Seat Static Comfort Level. China Academic Journal Electronic Publishing House

[31] S. Yuan. (N. A.) On the comfort of car seat. China Academic Journal Electronic Publishing House

[32] F. Fei. (N. A.) A Study of the Relation between the Adjustable Dimensions of Automobile Seat and Driving Comfort. China Academic Journal Electronic Publishing House

[33] J. Wang., H. Huang., X. Liu., L. Zhao., Y. Tao. (2011) Lightweight Design of Automotive. Journal of Shanghai University of Engineering Science, Vol 26, No 1, pp 15-18

[34] T. Yang. (2012) Optimal Design on Structure and Forming Process for Lightweight of Automobile Seats.

[35] X. Chen. (2007) The Application and Finite Element Analysis of Magnesium Alloy on Automobile Seat Structures. China Academic Journal Electronic Publishing House 